\title{
Quality Control and Evaluation of Certain Properties of Soaps Available in Butwal Sub- metropolitan City, Nepal
}

\author{
Krishna Prasad Sharma (Ph.D), Anil Belbase, Umesh Neupane*
}

\begin{abstract}
The maintenance of beautiful skin and hair is the desire of many people all over the world, thus, the application of safe cosmetic products is inevitable. Soap can play vital role in survival. In the present study, the quality determining physicochemical properties of different brands of soaps available in Butwal city were investigated. The minimum amount of moisture in soap provides the self life of the soaps. In this regard, Godrej No. 1 sandal and turmeric soap seems to be more reliable giving percentage moisture 11.68 followed by Dove white beauty bar soap (12.44\%) and Himalayan herbal soap (14.80\%). The high amount of total fatty matter helps for lubrication the skin during washing. The result showed that all the soaps, under study, fulfilled the standard set by Bureau of Indian Standard (BIS) except Okhati soap, which only gives $42.30 \%$ total fatty matter (TFM). The lower levels of total alkali indicate the quality of soaps since it provides harshness effect on skin. The presences of excess alkali were detected in all of the soaps and values lie above standard limit as set by the BIS. The higher $p H$ value indicates good lathering tendency of any soap. The $p H$ values of all soaps were higher than 9 except for Dove white beauty bar soap ( $p H=7.6)$, indicating high percentage amount of unspecified and unsaponiofication matter due to incomplete alkaline hydrolysis. However, all the soaps analyzed in this study meet the quality criteria set by Bureau of Indian Standards and can therefore be classified as been of good quality.
\end{abstract}

Keywords: quality control, Soap, Moisture content, total alkali, Total fatty matter, pH

\section{INTRODUCTION}

Soap may be defined as a chemical compound or mixture of chemical compounds resulting from the interaction of fatty acids or fatty glycerides with a metal radical or organic base (Habib et al., 2016). The properties of soap depend upon the no of carbon chain that is involved in saponification process. The long chain of fatty acids $\mathrm{C}_{16}-\mathrm{C}_{18}$ contributes detergency properties while that of $\mathrm{C}_{12}-\mathrm{C}_{14}$ fatty acids contribute lathering and washing properties of soap (Vidal et al., 2018). The physicochemical parameters of the soap which include color, total alkali content, total fatty matter, moisture content, conductivity and viscosity play a major roles in determining the efficiency and cleansing behavior of soaps while these parameters are governed by the factors like strength and purity of alkali, kind of oil used and completeness of saponification reaction. The phytochemical compounds present in soap reveal pharmacological properties which exerts a biochemical or physiological effect on the skin of users with less toxicity. Gfatter et al. (1997) studied the effect of soap and detergents on skin $\mathrm{pH}$ of infants and found increase in $\mathrm{pH}$ of skin after bathing the children. Vivian et al. (2014), studied the physicochemical properties of different brands of soaps and detergents, and found that such properties have played significance role in determining the quality of soaps and detergents based on their cleansing action.

*Department of Chemistry, Butwal Multiple Campus, Butwal 
The main functions of soaps and detergents are to remove the dirt adequately and prevent the spread of infectious disease. However these functions of soaps and detergents are lost when these substances bring adverse effect on skin. These effects include damage to the barrier function of skin, increased susceptibility to the environmental irritants and antigens, skin irritation with erythema and edema as well as reduction of moisture and smoothness of the skin (Ramairez, 2002). Recently, it has been found that normal use of an alkaline soap causes a small increase in $\mathrm{pH}$ of the skin which hinders in skin repairing (Korting et al., 1987). In addition, the application of sodium lauryl sulfate under occlusion with a solution with high $\mathrm{pH}$ causes a low but significant increase in transepidermal water loss (Pradhan \& Bhattacharya, 2017). The unreacted alkali present in soap, which causes bleaching action on skin, must be washed out during soap production. Unfortunately, most soap production industries sacrifice quality for profit and retain unreacted alkali in soap.

The monitoring of the precision and accuracy of analyses carried out in laboratory must be performed and cross checked by quality control programs and such programs must be operated in regional, provincial and national level. Unfortunately, no any progressive steps have been initiated by government to check the quality of soaps though this is the serious health issue in Nepal. Keeping these views in mind, the present study focuses on analysis of some physicochemical properties of soaps and detergents in their aqueous form available in Nepal.

\section{MATERIALS AND METHOD}

\section{Collection of samples}

The analysis was conducted on ten different brands of soap purchased from different areas in butwal sub-metropolitan city, Nepal. Soaps including; Dettol original bar soap (S1), Ashmi chiuree neem ayurveda soap (S2), Dove white beauty bar soap (S3), Lifebuoy nature skin cleansing soap (S4), Lux beauty soap (S5), Himalayan herbal soap (S6), Godrej No. 1 sandal and turmeric soap (S7), Patanjali Soap (S8), Liril lime \& tea tree oil soap (S9) and Okhati (S10) were subjected for various physicochemical tests.

\section{Determination of moisture content}

The moisture content of all the soaps under study was determined by using well established relation (Wilhelm et al., 1993). 5 gm of each soap sample was taken in clean and dried silica crucible, separately and left for 24 hours in desiccators containing lumps of silica gel. The crucibles were then transferred to oven and dried at $101^{\circ} \mathrm{C}$ for 2 hours. The samples were then cooled, weighed and the moisture content was calculated using equation below. Loss in weight is assumed to be moisture loss;

$$
\% \text { moisture content }=\frac{W s-W h}{W s-W w} \times 100
$$

where, $\mathrm{W}_{S}$ is the weight of crucible \& sample before drying, $\mathrm{W}_{h}$ is the weight of crucible \& sample after drying and $\mathrm{W}_{w}$ is the weight of crucible.

\section{Determination of Total alkali content}

The total alkali content in each sample of soap was determined by titrating excess acid present in soap emulsion with standard $\mathrm{NaOH}$ solution. $100 \mathrm{~mL}$ of soap emulsion of each sample was prepared by dissolving 10 gram of soap in ethanol. To the emulsion solution, $5 \mathrm{~mL}$ of $1 \mathrm{~N} \mathrm{H}_{2} \mathrm{SO} 4$ solution was added and heated to ensure the complete dissolution of soap particles. The test solution was then titrated against $1 \mathrm{~N} \mathrm{NaOH}$ using phenolphthalein indicator. The total alkali content was determined by the formula

$$
\% \text { Total alkali }=\frac{V A-V B}{W} \times 3.1
$$

where $\mathrm{V}_{A}$ and $\mathrm{V}_{B}$ are the volume of acid and base, respectively and $W$ is the weight of soap sample (Betsy et al., 2013).

\section{Determination of Total Fatty Mater}

Total fatty matter contained in soap sample was determined by using the techniques used by Onyekwere (1996). Soap emulsions were made by adding $10 \mathrm{~g}$ of soap in $150 \mathrm{~mL}$ distilled water and heated gently. To the emulsion $20 \mathrm{~mL}$ of $15 \% \mathrm{H}_{2} \mathrm{SO}_{4}$ was added and stirred until the clear emulsion was formed. The fatty matter is then solidified by adding $7 \mathrm{~g}$ of bee wax and allowed for heating and cooling process. The resulting substance, in the form of cake, is then allowed to dry and then weighed in order to calculate the TFM present in the soap by using the relation; 


$$
\% \mathrm{TFM}=\frac{A-X}{W} \times 100
$$

where $\mathrm{A}$ is the weight of wax and fatty matter, $\mathrm{X}$ is the weight of wax samples and $\mathrm{W}$ is the weight of soap after drying.

\section{Determination of $\mathbf{p H}$}

The hydrogen-ion activity of soap emulsion solutions of soap samples (S1 to S10) was measured by using $\mathrm{pH}$ meter (HI-98107 pH Tester). The soap emulsion solution was prepared by dissolving $100 \mathrm{mg}$ soap in $100 \mathrm{~mL}$ of distilled water. The resulting emulsion solution was left undisturbed for 24 hours to ensure the complete dissolution of soap. The instrument was calibrated by dipping the electrode in buffer solutions of $\mathrm{pH} 4$ and 9.2.

\section{RESULT AND DISCUSSION}

Physiochemical properties of ten commercial soaps (Sample S1 - S10) were estimated and their qualities evaluated. The chemical analysis includes onsite analysis (Moisture, $\mathrm{pH}$ ) and in-laboratory analysis (total alkali and TFM) of all samples. The results are shown in Table 1.

\begin{tabular}{|c|c|c|c|c|}
\hline Soap sample & \% Moisture & Total alkali \% & TFM \% & pH \\
\hline S1 & 26.44 & 1.24 & 76.92 & 9.5 \\
\hline S2 & 48.58 & 0.86 & 60.43 & 9.2 \\
\hline S3 & 12.44 & 0.93 & 91.40 & 7.6 \\
\hline S4 & 35.98 & 1.08 & 76.08 & 9.6 \\
\hline S5 & 27.08 & 1.24 & 60.70 & 9.7 \\
\hline S6 & 14.80 & 0.93 & 96.60 & 9.7 \\
\hline S7 & 11.68 & 1.17 & 91.00 & 9.6 \\
\hline S8 & 16.14 & 1.17 & 70.30 & 9.6 \\
\hline S10 & 23.70 & 1.08 & 70.4 & 9.5 \\
\hline S9 & 40.26 & 1.11 & 42.30 & 9.4 \\
\hline
\end{tabular}

Total moisture content in different brands of soaps is given in Figure 1. High moisture content in soap would lead to reaction of excess water with un-saponified fat to give free fatty acid and glycerol in a process called hydrolysis of soap on storage (Samuelsson, 2006). Result revealed that, soap S2 was found to have highest level of moisture content followed by soap $\mathbf{S 1 0 .}$

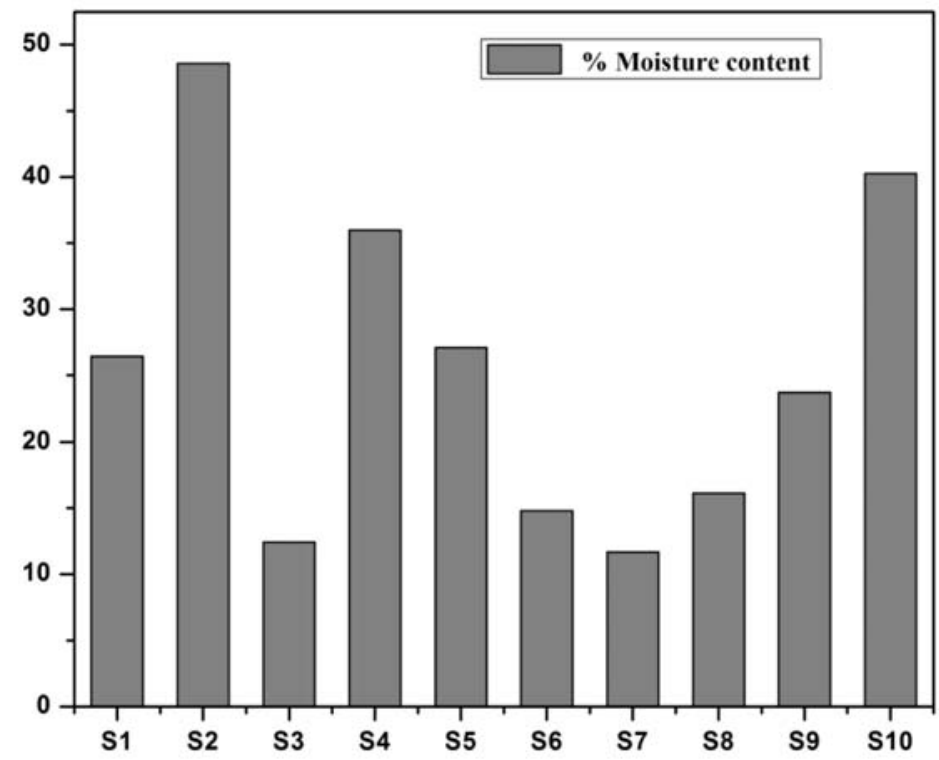

Figure 1: percentage moisture content is different brands of soaps 
Total alkali content in soap measures all alkaline substances present in soap. The free caustic alkali present in each sample of soap was determined by ethanol method and presented in Figure 2. It was found that S1 and S5 soaps contained high amount of free alkali (1.24\%) followed by S7 and S8 (1.178\%). S4, S9 and S10 soaps exhibited nearly the same amount of free alkali whereas S2, S3 and S6 soaps contained less than 1 $\%$ free alkali. According to International Standards Organization (ISO) guideline, the good quality of soaps must contain less than $2 \%$ of free alkali (Kisan et al., 1992. All the soap samples under investigation satisfied the standard level of alkali content set by ISO.

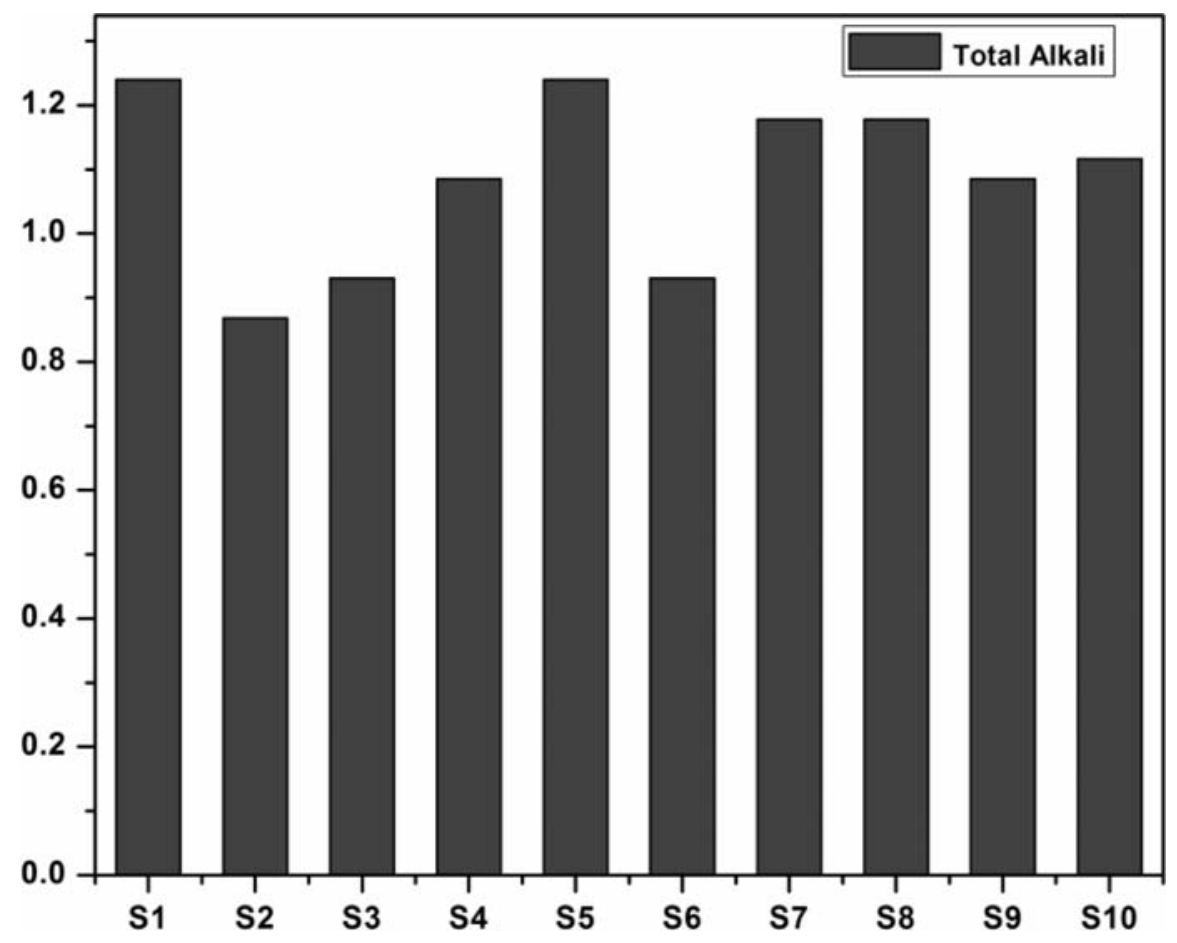

Figure 2: Total alkali content in different brands of soaps.

Total fatty matter (TFM) measures the amount of fatty matter contained in different brands soaps. It has proved that the soap having high TFM values determine the quality of soaps and gives more lather, lasts longer and more efficient cleansing action (Popescu et al., 2011). In addition, International Standard Organization set the criteria that the good quality of soaps must have TFM above $76 \%$. As such bathing soaps are categorized into three grades; Grade 1 soaps should have a minimum of $76 \%$ TFM, grade 2 soaps should have a minimum of $70 \%$ TFM and Grade 3 soaps must have a minimum of 60\% TFM (Arasaretnam \& Venujah, 2019). Total fatty matter (TFM) content in different soaps in this study was calculated and presented in Fig. 3. In our study, 5 brands of soaps (S1, S3, S4, S6 and S7) have achieved the grade 1 quality. The soap S6 has highest TFM values with $96.60 \%$ followed by S3 with $91.60 \%$. Four brands of soaps (S2, S5, S8 and S9) have ranked in grade 2 qualities while only one soap brand S10 has categorized into grade 3 . The different values of TFM of different brand of soaps might be due to differences in their moisture content, quality of fatty acids and saponification methods. 


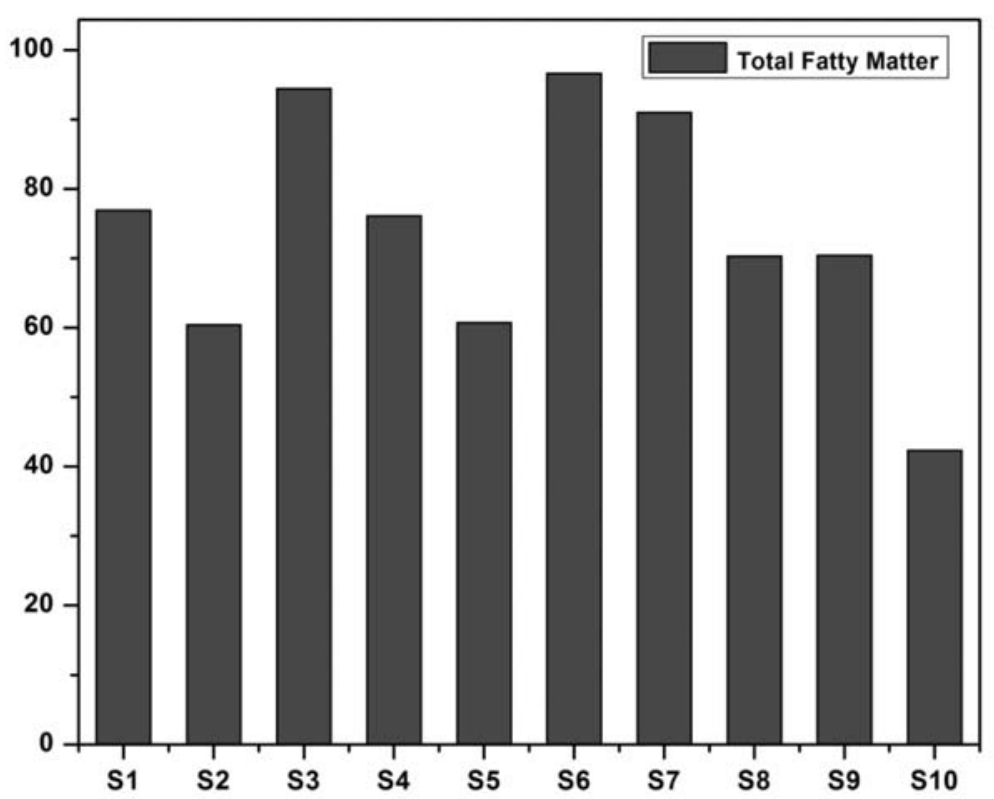

Figure 3: Total Fatty Matter of different brands of soaps

The $\mathrm{pH}$ is one of the important parameter of soap quality as it acts as a barrier against bacteria and viruses and plays a vital role in the pathogenesis of some skin diseases (Ali \& Vosiporitch, 2013). Chemically soap is a salt of weak acid and strong base thus behaves as alkaline when dissolved in water. It is found that $\mathrm{pH}$ values of most of the milder bathing soaps lie in between 8-10. The study shows that healthy skin has a $\mathrm{pH}$ of 5.4 to 5.9, while the body's internal environment maintains a pH of 7-9 (Community, 2011). Figure 4 shows the $\mathrm{pH}$ measurements of different soap samples under the present study. The $\mathrm{pH}$ values of all soaps are found to be in the range between 7.6 and 9.7, where the lowest and higher values are from samples S3 and S6 \& S7. Increase in $\mathrm{pH}$ is due to the incomplete hydrolysis during saponification process. Increase in $\mathrm{pH}$ causes an increase in skin dehydration, irritability and bacterial flora (Information, 2012). The values obtained in this study were compared with the values of standard literature and found all the values within their standard range except S3.

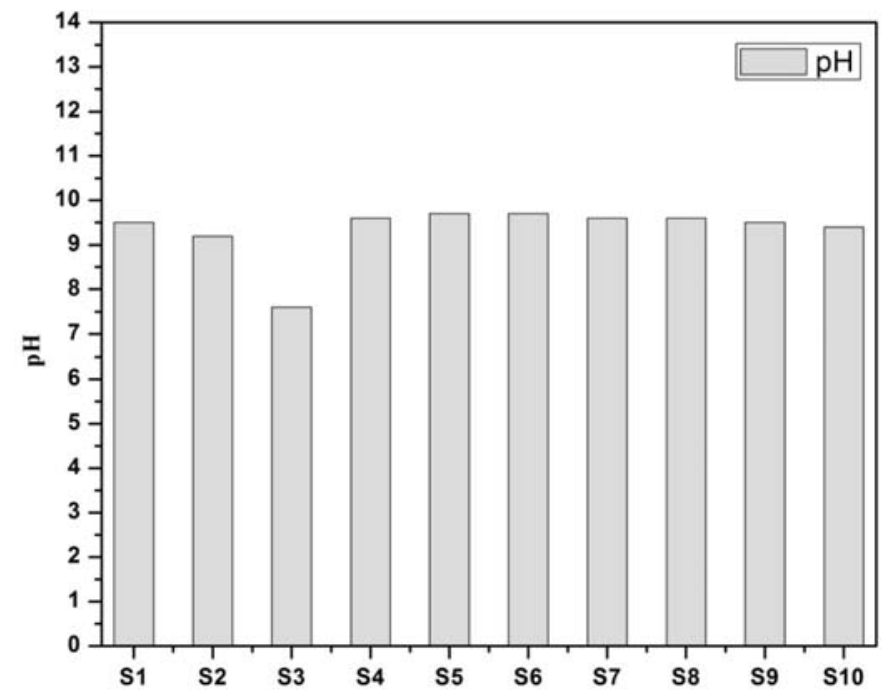

Figure 4: $\mathrm{pH}$ of different brands of soaps. 


\section{CONCLUSION}

The physicochemical properties of soaps available in Butwal city were analyzed to compare the values on quality criteria for the moisture content, total alkali content, content of total fat and $\mathrm{pH}$. The obtained results reveals similarities in parameters like $\mathrm{pH}$, moisture, free alkali, and total fat for all brands of soaps. The minimum amount of moisture in soap provides the hardiness of the soaps. In this regard, Godrej No. 1 sandal and turmeric soap seem to be more reliable giving percentage moisture 11.68 followed by Dove white beauty bar soap (12.44 \%) and Himalayan herbal soap (14.80 \%). The high amount of total fatty matter helps for lubrication the skin during washing. The result showed that all the soaps under the present study, fulfilled the standard set by BIS except Okhati soap, which only gives $42.30 \%$ TFM. However, TFM of Dettol original bar soap, Dove white beauty bar soap, Lifebuoy nature skin cleansing soap, Himalayan herbal soap and Godrej No. 1 sandal and turmeric soap is above $76 \%$ and may be considered as grade 1 soaps. Himalayan herbal soap is the most lubricating soap among other soaps under study. Similarly, Patanjali soap, Liril lime \& tea tree oil soap fall under grade 2 quality whereas Ashmi chiuree neem ayurveda soap and Lux beauty soaps may be considered to be grade 3 qualities. The lower levels of total alkali indicate harshness effect on skin. The presences of excess alkali were detected in all of the soaps and values lie above standard limit as set by the BIS. Since the amounts of the alkali present are in accepted levels, they cannot be classified as harmful soaps. The higher $\mathrm{pH}$ value indicates good lathering tendency of any soap. The $\mathrm{pH}$ values of all soaps were higher than 9 except for Dove white beauty bar soap $(\mathrm{pH}=7.6)$, indicating high percentage amount of unspecified and unsaponiofication matter due to incomplete alkaline hydrolysis. Hence, it can be concluded from the study that all the soaps analyzed meet the quality criteria set by Bureau of Indian Standards and can therefore be considered as safe for use.

\section{Acknowledgement}

The authors are thankful to Department of Chemistry, Butwal Multiple Campus for providing instrumental facilities.

\section{References}

Al Badi, K., \& Khan, S. A. (2014). Formulation, evaluation and comparison of the herbal shampoo with the commercial shampoos. Journal of Basic and Applied Sciences, 3(4), 301-305.

Ali, S. M., \& Yosipovitch, G. (2013). Skin pH: from basic science to basic skin care. Acta dermato-venereologica, 93(3), 261-269.

Arasaretnam, S., \& Venujah, K. (2019). Preparation of Soaps by Using Different Oil and Analyze their Properties. Nat Prod Chem Res, 7 (357), 2-4.

Ashrafy Habib, S. K., Sorowar, M. S., Karmoker, J., Khatun, M. K., \& Al-Reza, S. M (2016). Study on the Physicochemical Properties of Some Commercial Soaps Available in Bangladeshi Market. International Journal of Advanced Research in Chemical Science. 3 (6), 9-12.

Betsy, K. J., Jilu, M., Fathima, R., \& Varkey, J. T. (2013). Determination of Alkali Content \& Total Fatty Matter in Cleansing Agents. Asian Journal of Science and Applied Technology, 2(1), 8-12. Cavitch, Q. \& Susan, M. (1994). The Natural Soap Book. Storey Publishing (pp.234-263). ISBN 0-88266-888-9. EAS 031:1997, East African harmonised standard specification for Laundry soap

Gfatter, R., Hackl, P., \& Braun, F. (1997). Effects of soap and detergents on skin surface pH, stratum corneum hydration and fat content in infants. Dermatology, 195(3), 258-262. 
Hasan S, Rehman H, Saddique A, Gul M, Ullah A, (2017). Physiochemical analysis of soap and shampoo collected from local market of karak district, Pakistan. World Applied Sciences journal 35 (9), 2012 2014.

Indian Standard Laundary soaps-specification, Third reprint, https:/law.resource.org/pub/in/bis/S02/is.285.1992

Korting, H. C., Kober, M., Mueller, M., \& Braun-Falco, O. (1987). Influence of repeated washings with soap and synthetic detergents on $\mathrm{pH}$ and resident flora of the skin of forehead and forearm. Results of a crossover trial in health probationers. Acta dermato-venereologica, 67 (1), 41-47.

Mak-Mensah E. E. \& Firempong C. K. (2011). Chemical characteristics of toilet soap prepared from neem (Azadirachta indica A. Juss) seed oil. Asian Journal of Plant Science and Research, 1 (4), 1-7 Onyekwere, C. (1996). Cassava peels ash: An alternative source of alkali in soap production. BEng Thesis, 1-33.

Popescu, V., Soceanu, A., Dobrinas, S., Stanciu, G., \& Epure, D. T. (2011). Quality control and evaluation of certain Properties for soaps made in Romania. Scientific Study \& Research. Chemistry \& Chemical Engineering, Biotechnology, Food Industry, 12(3), 257.

Prieto Vidal, N., Adeseun Adigun, O., Pham, T. H., Mumtaz, A., Manful, C., Callahan, G., \& Thomas, R. H. (2018). The Effects of Cold Saponification on the Unsaponified Fatty Acid Composition and Sensory Perception of Commercial Natural Herbal Soaps. Molecules, 23(9), 2356.

Samuelsson, R., Burvall, J., \& Jirjis, R. (2006). Comparison of different methods for the determination of moisture content in biomass. Biomass and Bioenergy, 30 (11), 929-934.

Vivian, O. P., Nathan, O., Osano, A., Mesopirr, L., \& Omwoyo, W. N. (2014). Assessment of the physicochemical properties of selected commercial soaps manufactured and sold in Kenya. Open Journal of Applied Science. 4, 433-440.

Wilhelm, K. P., Cua, A. B., Wolff, H. H., \& Maibach, H. I. (1993). Surfactant-induced stratum corneum hydration in vivo: prediction of the irritation potential of anionic surfactants. Journal of investigative dermatology, 101(3), 310-315. 